\title{
Culture pH interacts with corn oil concentration to affect biohydrogenation of unsaturated fatty acids and disappearance of neutral detergent fiber in batch culture
}

\author{
Y. Sun, M. S. Allen, and A. L. Lock* \\ Department of Animal Science, Michigan State University, East Lansing 48824
}

\section{ABSTRACT}

Effects of culture $\mathrm{pH}$ and corn oil (CO) concentration on biohydrogenation $(\mathrm{BH})$ of unsaturated fatty acids and disappearance of neutral detergent fiber $(\mathrm{NDF})$ in batch culture were evaluated in a $2 \times 3 \mathrm{fac}-$ torial design experiment. Culture vessels $(100 \mathrm{~mL} ; 4$ replicates/treatment per time point) included ground alfalfa hay plus CO at 0,1 , or $2 \%$ dry matter inclusion rate and were incubated at $\mathrm{pH} 5.8$ (low $\mathrm{pH}$ ) or 6.2 (high $\mathrm{pH}$ ) for $0,6,12,18$, or $24 \mathrm{~h}$. Effects of culture $\mathrm{pH}, \mathrm{CO}$, time, and their interactions were determined. Adding $\mathrm{CO}$ increased total fatty acid concentration in substrates to $1.01,2.31$, and $3.58 \%$ dry matter for 0,1 , and $2 \% \mathrm{CO}$, respectively. Corn oil concentration interacted with culture $\mathrm{pH}$ and resulted in different effects on $\mathrm{BH}$ of cis-9,cis-12 18:2 at low or high culture $\mathrm{pH}$. After $24 \mathrm{~h}$ of incubation, low $\mathrm{pH}$, compared with high $\mathrm{pH}$, reduced disappearance of NDF by $35 \%$ and $\mathrm{BH}$ extent of cis-9,cis-12 18:2 by $31 \%$. Increasing $\mathrm{CO}$ increased disappearance of NDF across $\mathrm{pH}$ treatments and decreased BH extent of cis-9,cis-12 18:2 at low $\mathrm{pH}$ and increased it at high $\mathrm{pH}$ over $24 \mathrm{~h}$. Compared with high $\mathrm{pH}$, low $\mathrm{pH}$ reduced concentrations of 18:0 by $31 \%$ and increased concentrations of trans-10, cis-12 18:2 and trans-10 18:1 by 110 and $79 \%$ after $24 \mathrm{~h}$, respectively. Adding $\mathrm{CO}$ at low $\mathrm{pH}$ had greater effect on $\mathrm{BH}$ intermediates of cis-9,cis-12 18:2 compared with adding oil at high $\mathrm{pH}$. In particular, increasing $\mathrm{CO}$ to 1 and $2 \% \mathrm{DM}$ at low $\mathrm{pH}$, compared with at high $\mathrm{pH}$, resulted in a 36 and $46 \%$ reduction in the concentration of 18:0, an 84 and $131 \%$ increase in the concentration of trans-10,cis-12 18:2, and an 81 and $129 \%$ increase in the concentration of trans-10 18:1, respectively. Despite the interactions between culture $\mathrm{pH}$ and $\mathrm{CO}$ concentration, main effects across time were also significant for the response variables of interest. In conclusion, culture

Received March 7, 2019.

Accepted June 28, 2019.

*Corresponding author: allock@msu.edu
$\mathrm{pH}$ interacted with $\mathrm{CO}$ concentration to affect $\mathrm{BH}$ of UFA and disappearance of NDF in batch culture, as the effects were greater at low culture $\mathrm{pH}$ than at high culture $\mathrm{pH}$.

Key words: batch culture, biohydrogenation, fatty acid

\section{INTRODUCTION}

Milk fat yield is one of the major determinants of milk income. Compared with other milk components, fat is the most sensitive to changes in diets and environment. Diet-induced milk fat depression (MFD) is defined as a reduction of up to $50 \%$ in milk fat yield with no change in the yield of milk and other milk components (Bauman et al., 2011). Rumen bacteria biohydrogenate UFA in the rumen and produce various fatty acid (FA) intermediates (Shingfield and Wallace, 2014). In most situations, diet-induced MFD is caused by the inhibition of milk fat synthesis in the mammary gland by specific rumen PUFA biohydrogenation $(\mathbf{B H})$ intermediates (Bauman et al., 2011). Among known BH intermediates, trans-10,cis-12 18:2 has been well characterized as a potent inhibitor of milk fat synthesis (Bauman et al., 2011) and trans-10 18:1 in milk is correlated with reductions in milk fat concentration (Bauman et al., 2011).

Linoleic acid (cis-9, cis-12 18:2) is an abundant dietary FA for dairy cows. Rumen bacteria biohydrogenate cis-9,cis-12 18:2 with cis-9,trans-11 18:2 and trans-11 18:1 as major intermediates. However, other intermediates are also produced during $\mathrm{BH}$ of cis-9, cis-12 18:2 (Honkanen et al., 2012). Changes in diet and the rumen environment can cause more cis-9,cis-12 18:2 to be converted to trans-10,cis-12 18:2 and trans-10 18:1 (Bauman et al., 2011). Furthermore, rumen pH and milk fat percentage are highly positively correlated (Allen, 1997), potentially due to differential inhibition of different species of rumen bacteria (Russell and Dombrowski, 1980). Several in vitro studies have tested the effects of $\mathrm{pH}$ on $\mathrm{BH}$ of UFA and have shown that 
low $\mathrm{pH}$ inhibited $\mathrm{BH}$ and increased formation of trans10,cis-12 18:2 (Troegeler-Meynadier et al., 2003, 2014; Fuentes et al., 2011). Previous in vitro incubation studies have found that increasing cis-9,cis-12 18:2 inhibits BH of cis-9,cis-12 18:2 to 18:0 (Troegeler-Meynadier et al., 2003; Honkanen et al., 2012), potentially through an inhibition of Butyrivibrio fibrisolvens growth (Kim et al., 2000).

Most published studies, however, do not take into account the interactions between dietary and ruminal factors. Typically, dietary changes will affect the rumen environment, and the combinations of those alterations may increase the risk of MFD. Van Nevel and Demeyer (1996) determined the influence of $\mathrm{pH}$ and soybean oil level on triglyceride hydrolysis and $\mathrm{BH}$ in vitro and found that compared with $\mathrm{BH}$, hydrolysis was more sensitive to low $\mathrm{pH}$, especially with increased inclusion of soybean oil. However, no nutritive substrate other than soybean oil was included in the cultures, and no specific FA intermediates of $\mathrm{BH}$ were reported. The presence of a fibrous substrate is essential to better represent the complex metabolism present in the rumen, and quantification of $\mathrm{BH}$ intermediates is necessary to discern possible effects of dietary and rumen factors on milk fat synthesis. Therefore, additional research is necessary to assess the effect of rumen $\mathrm{pH}$ and dietary UFA on the production of $\mathrm{BH}$ intermediates associated with MFD. The objective of our study was to determine the interactions of $\mathrm{pH}$ and corn oil $(\mathbf{C O})$, as a source of cis-9,cis-12 18:2, at common dietary concentrations on $\mathrm{BH}$ and NDF disappearance using an in vitro batch culture method. We hypothesized that rumen $\mathrm{pH}$ and $\mathrm{CO}$ concentration would interact to affect $\mathrm{BH}$ of cis-9,cis-12 18:2 and disappearance of NDF in batch cultures. Furthermore, we hypothesized that increasing cis-9, cis-12 18:2 at a low $\mathrm{pH}$ would cause greater inhibition of $\mathrm{BH}$ compared with a high-pH environment and increase formation of trans-10,cis-12 18:2 and trans-10 18:1.

\section{MATERIALS AND METHODS}

\section{Treatment and Incubation}

Our experiment used a $2 \times 3$ factorial arrangement of treatments: 2 culture $\mathrm{pH}$ levels (low $\mathrm{pH}=5.8$; high $\mathrm{pH}=6.2)$ and $3 \mathrm{CO}$ concentrations $(0,1$, or $2 \% \mathrm{DM}$ inclusion rate). All cultures were run in quadruplicate, with 2 analyzed for NDF residue and 2 for FA concentrations. All cultures contained alfalfa hay $(41.0 \%$ NDF and 1.01\% FA, DM basis) as the base substrate, which was dried at $55^{\circ} \mathrm{C}$ for $48 \mathrm{~h}$ and ground through a 1-mm screen using a Wiley mill (Arthur H. Thomas, Philadelphia, PA). The $0 \% \mathrm{CO}$ treatment was alfalfa
Table 1. Fatty acid (FA) profile and total FA content of alfalfa hay containing corn oil $(\mathrm{CO})$ used in the in vitro batch cultures

\begin{tabular}{|c|c|c|c|}
\hline \multirow[b]{2}{*}{ Item } & \multicolumn{3}{|c|}{ CO concentration } \\
\hline & $0 \%$ & $1 \%$ & $2 \%$ \\
\hline \multicolumn{4}{|l|}{$\overline{\mathrm{FA}}, \mathrm{g} / 100 \mathrm{~g}$ of total FA } \\
\hline $16: 0$ & 31.0 & 19.9 & 16.7 \\
\hline 18:0 & 5.27 & 3.30 & 2.76 \\
\hline cis-9 18:1 & 4.37 & 17.9 & 21.8 \\
\hline cis-9,cis-12 18:2 & 18.4 & 39.0 & 44.8 \\
\hline cis-9, cis-12, cis-15 18:3 & 19.7 & 9.41 & 6.49 \\
\hline $22: 0$ & 2.20 & 1.03 & 0.69 \\
\hline 24:0 & 2.03 & 1.00 & 0.68 \\
\hline$\Sigma$ Unknown & 5.45 & 2.48 & 1.66 \\
\hline$\Sigma$ Others & 11.49 & 6.00 & 4.43 \\
\hline Total FA, $\%$ of DM & 1.01 & 2.31 & 3.58 \\
\hline
\end{tabular}

hay containing no CO. Rather than adding oil directly to cultures, alfalfa hay containing $2 \% \mathrm{CO}$ on a DM basis was prepared by spraying CO (Mazola, ACH Food Companies Inc., Memphis TN) in ethanol onto the corresponding weight of alfalfa hay. The alfalfa hay plus $\mathrm{CO}$ was mixed well during spraying, dried at $55^{\circ} \mathrm{C}$ to evaporate the ethanol, and ground through a 1-mm screen using a Wiley mill (Arthur H. Thomas) for consistency. Alfalfa hay containing $1 \% \mathrm{CO}$ was prepared by combining alfalfa hay with prepared alfalfa hay containing $2 \% \mathrm{CO}$ in 1:1 ratio. The FA content and profile were analyzed for alfalfa hay containing $\mathrm{CO}$ $(0,1$, or $2 \%)$ after grinding, and the results are shown in Table 1.

Three rumen-fistulated mid-lactation Holstein dairy cows $(185 \pm 9$ DIM) fed a common TMR ( $27 \%$ corn silage, $14 \%$ alfalfa silage, $20 \%$ ground corn, $17 \%$ soybean meal, $7 \%$ high moisture corn, $7 \%$ cottonseed, $2 \%$ soy hulls, $3 \%$ wheat straw, $3 \%$ minerals and vitamins) were used as rumen inoculum donors for this study. Rumen fluid and solid digesta from 3 cows were collected $1 \mathrm{~h}$ after feeding, pooled and transported in a prewarmed Thermos container, and blended in a 1-gallon Waring blender at low speed for $25 \mathrm{~s}$ to detach the bacteria from the feed particles. The blended mixture was then passed through a Buchner funnel lined with nylon mesh and glass wool to trap large particles, which were discarded. The strained rumen fluid was transferred to a 500-mL Brinkman pipette bottle for inoculating individual culture tubes. The rumen fluid was continuously flushed with $\mathrm{CO}_{2}$ during all procedures.

All cultures were prepared as described by Goering and Van Soest (1970). Sayre and Van Soest (1972) previously reported that using large glass tubes (200 $\times 25 \mathrm{~mm}$ ) as incubation vessels yielded similar NDF disappearance results compared with 125-mL Erlenmeyer flask vessels, which are more typical for in vitro artificial rumen procedures. In the present study, we 
used Pyrex centrifuge tubes $(100 \mathrm{~mL})$ as incubation vessels. Volumes of $1 \mathrm{M}$ citric acid $(\sim 0.14$ and $0.27 \mathrm{~g} /$ culture) were added to the medium solution to adjust $\mathrm{pH}$ to 5.8 or 6.2 , as described by Grant and Mertens (1992a). Each vessel contained $500 \mathrm{mg}$ of alfalfa hay with 0,1 , or $2 \% \mathrm{CO}, 40 \mathrm{~mL}$ of medium solution $(\mathrm{pH} 5.8$ or 6.2), $2 \mathrm{~mL}$ of reducing solution, and $10 \mathrm{~mL}$ of rumen fluid. All vessels were swirled gently by hand to ensure that substrate and liquid were well mixed after addition of medium solution, reducing solution, and rumen fluid. The estimated time between rumen fluid collection to completion of inoculations was $40 \mathrm{~min}$. The starting $\mathrm{pH}$ of low-pH and high-pH cultures was $5.78 \pm 0.01$ and $6.17 \pm 0.02$, respectively. Weight of alfalfa hay and oil mixtures in each culture was recorded for calculations of $\mathrm{BH}$ extent of cis-9,cis-12 18:2 and disappearance of NDF. Culture tubes were flushed with $\mathrm{CO}_{2}$ and sealed with 5.5-cm rubber stoppers connected to a Bunsen valve to release excessive gas during incubation. All cultures were incubated in the same water bath with no agitation at $39^{\circ} \mathrm{C}$ and were swirled gently by hand at $6 \mathrm{~h}$ of incubation.

Incubation of cultures was stopped at $0,6,12,18$, and $24 \mathrm{~h}$. Immediately after rumen fluid inoculation, culture tubes taken at $0 \mathrm{~h}$ were placed in an ice bath and dry ice was added to each vessel to stop enzyme activity. At $6,12,18$, and $24 \mathrm{~h}$, incubations were also terminated as described above. The $\mathrm{pH}$ of all culture tubes was tested immediately before incubations were terminated. Culture tubes for NDF residue analysis were placed in a $4^{\circ} \mathrm{C}$ cooler until analysis (completed within $48 \mathrm{~h}$ ). Culture tubes for FA composition analysis were stored at $-20^{\circ} \mathrm{C}$ and subsequently freeze-dried.

\section{Chemical Analyses}

The NDF residue was analyzed as described by Mertens (2002) to determine disappearance of NDF as described in the subsequent section. To ensure an accurate analysis of FA content, samples were directly freeze-dried and methylated in the culture tubes using a 2-step methylation protocol adapted from Jenkins (2010). Internal standard (17:0, 1:1 mg/mL toluene) was added to cultures after the incubation was terminated and before storage at $-20^{\circ} \mathrm{C}$. To determine the dry culture content weight, all tubes were preweighed and reweighed after being freeze-dried. Freeze-dried samples were mixed with $8 \mathrm{~mL}$ of $0.5 M$ sodium methoxide solution in methanol and incubated for 10 min in a $50^{\circ} \mathrm{C}$ water bath. After tubes cooled, $12 \mathrm{~mL}$ of $5 \%$ methanolic hydrochloric acid solution was added, followed by $10 \mathrm{~min}$ of incubation in an $80^{\circ} \mathrm{C}$ water bath. After tubes were removed from the water bath and cooled, $10 \mathrm{~mL}$ of hexane and $30 \mathrm{~mL}$ of $6 \% \mathrm{~K}_{2} \mathrm{CO}_{3}$ solution was added and the solution was mixed by vortexing. Tubes were centrifuged for $10 \mathrm{~min}$ at 6,000 $\times g$ at room temperature, and the hexane layer containing FAME was transferred to a $15-\mathrm{mL}$ centrifuge tube containing $2 \mathrm{~g}$ of sodium sulfate. The FAME were extracted again by adding $5 \mathrm{~mL}$ of hexane to the tubes and repeating the mixing, centrifuging, and transferring steps described above. The $15-\mathrm{mL}$ centrifuge tubes were inverted, and the samples were allowed to settle for 10 min. The solution was filtered through silica gel and charcoal to remove the sodium sulfate, and the solvent was evaporated with nitrogen gas at $37^{\circ} \mathrm{C}$. The FAME samples were weighed, and a $1 \%$ solution was prepared with hexane based on weight. The 1\% FAME solution was transferred to 2-mL GLC vials for analysis.

Fatty acid composition was determined using a GC-2010 Plus gas chromatograph (Shimadzu, Kyoto, Japan) with a split injector (1:100 split ratio) and a flame ionization detector (FID) using a CP-Sill 88 wall-coated open tubular fused-silica column $(100 \mathrm{~m} \times$ 0.25-mm i.d. $\times 0.2-\mu \mathrm{m}$ film thickness; Varian Inc., Lake Forest, CA). The carrier gas was hydrogen at a flow rate of $1 \mathrm{~mL} / \mathrm{min}$. Hydrogen, purified air, and nitrogen makeup gas were used as the FID gases at flow rates of 40,400 , and $30 \mathrm{~mL} / \mathrm{min}$, respectively. Injector and detector temperatures were $270^{\circ} \mathrm{C}$. The oven program was as follows: initial temperature held for $0.5 \mathrm{~min}$ at $40^{\circ} \mathrm{C}$, programmed to increase to $155^{\circ} \mathrm{C}$ at $25^{\circ} \mathrm{C} / \mathrm{min}$ and held for $30 \mathrm{~min}$, and then increased to $215^{\circ} \mathrm{C}$ at $4^{\circ} \mathrm{C} / \mathrm{min}$ and held for $35 \mathrm{~min}$. Injection volume was $1 \mu \mathrm{L}$. The FID response was the basis for integration and quantification (GCsolution software version 2.32.00; Shimadzu). Known FAME standards (GLC reference standard 463, GLC reference standard 481-B, and conjugated octadecadienoic mixture no. UC-59-M from Nu-Chek Prep Inc., Elysian, MN; Supelco 37 component FAME mix, cis/trans FAME mix, bacterial acid methyl ester mix, and PUFA No. 2 mix from Supelco Inc., Bellefonte, PA) were used for determination of individual FAME by comparing retention times. Quantification of FA covered approximately 45 individual FA in the range of 12:0 to $24: 0$.

\section{Calculations and Statistical Analysis}

Disappearance of NDF at each time point was calculated by subtracting the weight of NDF remaining after $6,12,18$, and $24 \mathrm{~h}$ of incubation from the weight at 0 $\mathrm{h}$ and dividing by the weight at $0 \mathrm{~h}$. This provided the percentage of NDF disappearance at each time point. Extent of BH was calculated by subtracting the weight of cis-9,cis-12 18:2 in the cultures at $6,12,18$, and $24 \mathrm{~h}$ from the weight at $0 \mathrm{~h}$ and dividing by the weight at 0 h. Similarly, this provided the percentage of cis-9, cis-12 
18:2 disappearance at each time point compared with $0 \mathrm{~h}$.

All data were analyzed using the fit model procedure of JMP (version 10, SAS Institute Inc., Cary, NC). The $\mathrm{pH}$, disappearance of $\mathrm{NDF}$, extent of $\mathrm{BH}$, total FA content, and FA concentrations of in vitro batch cultures over $24 \mathrm{~h}$ of incubation were analyzed using a model that contained the main effects of culture $\mathrm{pH}$, $\mathrm{CO}$ concentration, time, and the interactions of culture $\mathrm{pH} \times$ time, $\mathrm{CO} \times$ time, culture $\mathrm{pH} \times \mathrm{CO}$, and culture $\mathrm{pH} \times \mathrm{CO} \times$ time. To test the treatment effect after 24 $\mathrm{h}$ of incubation on these variables, results obtained at $24 \mathrm{~h}$ were analyzed separately using the same model but without the interactions of culture $\mathrm{pH} \times$ time, $\mathrm{CO}$ $\times$ time, and culture $\mathrm{pH} \times \mathrm{CO} \times$ time. Least squares means with standard error are reported. Significance was declared at $P<0.05$ and tendencies were declared at $P<0.10$ for main and interaction effects.

\section{RESULTS}

\section{FA Profile and Total FA Content of Substrates}

Total FA content and FA profile of alfalfa with different $\mathrm{CO}$ concentrations are shown in Table 1. Adding 1 and $2 \%$ of DM CO into alfalfa hay increased total FA by 1.30 and $2.57 \%$ of DM, respectively. As expected, increasing CO increased concentrations of cis-9 18:1 and cis-9,cis-12 18:2 and decreased concentrations of 16:0, 18:0, and cis-9,cis-12,cis-15 18:3.

\section{$p H$, Disappearance of NDF, and BH Extent of In Vitro Cultures}

Overall effects of treatments on $\mathrm{pH}$, disappearance of NDF, BH extent of cis-9,cis-12 18:2, and total FA content over $24 \mathrm{~h}$ of incubation are shown in Table 2; effects of treatments on those variables after $24 \mathrm{~h}$ of incubation are shown in Supplemental Table S1 (https: //doi.org/10.3168/jds.2019-16581). Increasing CO increased total FA content of cultures at both low and high $\mathrm{pH}(P<0.001)$ over $24 \mathrm{~h}$ of incubation. Although we observed interactions of $\mathrm{pH} \times \mathrm{CO}, \mathrm{pH} \times$ time, and $\mathrm{CO} \times$ time on total FA content $(P<0.05)$, the changes were less than $0.25 \mathrm{mg} /$ culture at the different $\mathrm{CO}$ inclusions (Table 2). Over $24 \mathrm{~h}$ of incubation, culture $\mathrm{pH}$ and $\mathrm{CO}$ interacted with time to affect $\mathrm{pH}$, disappearance of NDF, and $\mathrm{BH}$ extent of cis-9,cis-12 18:2 (Figures 1, 2, and 3). Overall, the $\mathrm{pH}$ of all cultures fluctuated during incubation, and average $\mathrm{pH}$ difference between low-pH and high-pH cultures remained over 0.2 unit over time (Table $2 ; 5.94$ vs. $6.19, P<$ 0.001 ), and after $24 \mathrm{~h}$ of incubation the average $\mathrm{pH}$ of low-pH and high-pH cultures was 6.06 and 6.21, respectively $(P<0.001)$. Corn oil concentration and time also interacted to affect culture $\mathrm{pH}(P<0.001)$, but the effects were minor (maximum changes in $\mathrm{pH}$ were 0.05 ) and $\mathrm{CO}$ had no effect on culture $\mathrm{pH}$ after $24 \mathrm{~h}$ of incubation (Supplemental Table S1, https://doi .org/10.3168/jds.2019-16581). Disappearance of NDF increased throughout incubations (Figure 2) and was higher in high-pH compared with low-pH cultures over time $(P<0.001$, Table 2$)$. After $24 \mathrm{~h}$ of incubation, low $\mathrm{pH}$ decreased NDF disappearance compared with high $\mathrm{pH}(22.7$ vs. $34.9 \%, P<0.001)$. Increasing $\mathrm{CO}$ increased NDF disappearance $(25.4,29.0$, and $32.1 \%$ for 0,1 , and $2 \%$ CO respectively; $P<0.001$ ) after 24 $\mathrm{h}$ of incubation. Over $24 \mathrm{~h}$ of incubation, we observed interactions between $\mathrm{pH}$ and $\mathrm{CO}(P<0.001)$ on $\mathrm{BH}$ extent. At low $\mathrm{pH}$, adding $\mathrm{CO}$ decreased $\mathrm{BH}$ extent compared with $0 \% \mathrm{CO}(P<0.001)$; at high $\mathrm{pH}$, adding $\mathrm{CO}$ increased $\mathrm{BH}$ extent compared with $0 \% \mathrm{CO}(P<$ $0.001)$. There was no difference between 1 and $2 \%$ CO. Similar to disappearance of NDF, BH extent increased throughout incubations (Figure 3) and was higher in high-pH cultures than in low-pH cultures over time $(P$ $<0.001$, Table 2). After $24 \mathrm{~h}$ of incubation, low $\mathrm{pH}$ decreased $\mathrm{BH}$ extent by $31 \%(P<0.001)$ compared with high $\mathrm{pH}$.

\section{Effects of Culture $\mathrm{pH}$ and CO on FA Profile of Cultures over 24 h of Incubation}

Results followed a similar pattern for FA if reported as grams per 100 grams of FA or milligrams per culture. Therefore, we only report the results for FA profile and focus on individual FA associated with BH of cis-9, cis-12 18:2. Due to the dynamic changes in FA profile during incubation, we mainly focus on the overall effects on FA over $24 \mathrm{~h}$ (Table 3) and temporal changes during $24 \mathrm{~h}$ of incubation (Figures 4, 5, and 6). Supplemental Table S2 (https://doi.org/10.3168/jds.2019-16581) shows FA profiles after $24 \mathrm{~h}$ of incubation.

Culture $\mathrm{pH}$ interacted with $\mathrm{CO}$ to alter the FA profile of cultures over $24 \mathrm{~h}$ of incubation (Table 3 ). Compared with $0 \%, \mathrm{CO}$ at 1 and $2 \%$ of DM increased cis-9, cis- 12 $18: 2$ by 141 and $217 \%$ at low $\mathrm{pH}(P<0.001)$, respectively; at high $\mathrm{pH}, 1$ and $2 \% \mathrm{CO}$ increased cis-9, cis-12 18:2 by 97 and $164 \%(P<0.001)$, respectively. Compared with $0 \%, \mathrm{CO}$ at 1 and $2 \%$ decreased 18:0 by 32 and $48 \%$ at low pH $(P<0.001)$, respectively; at high $\mathrm{pH}, 1$ and $2 \% \mathrm{CO}$ decreased 18:0 by 17 and $33 \%(P<$ $0.001)$, respectively. Compared with $0 \%, 1$ and $2 \% \mathrm{CO}$ increased trans-11 $18: 1$ by 40 and $47 \%$ at low $\mathrm{pH}(P<$ $0.001)$, respectively, and by 102 and $161 \%$ at high $\mathrm{pH}$ $(P<0.001)$, respectively.

Overall, compared with high $\mathrm{pH}$, low $\mathrm{pH}$ increased concentrations of cis-9,cis-12 18:2 (18.4 vs. $13.8 \mathrm{~g} / 100$ 


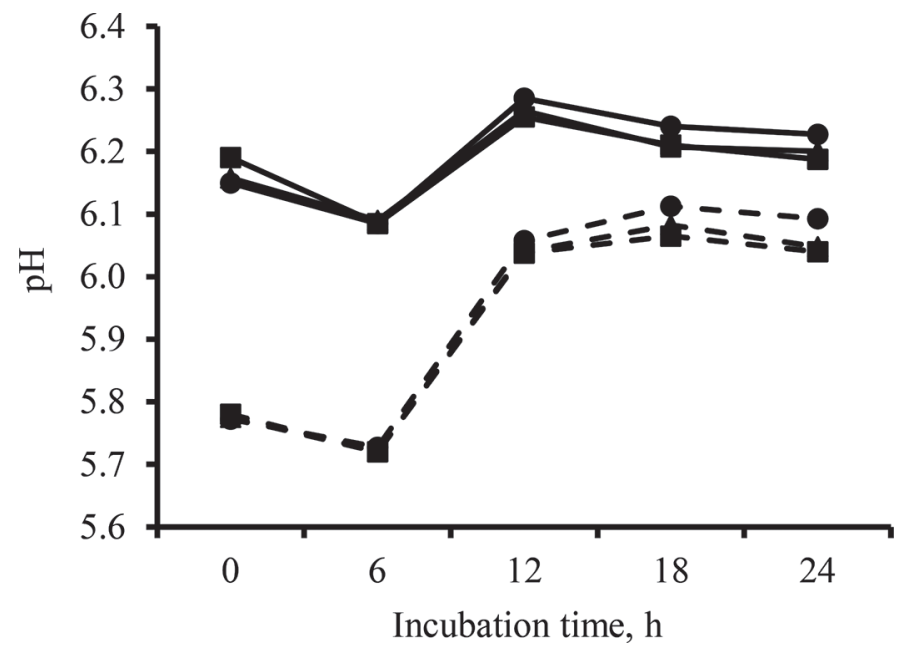

Figure 1. The pH of cultures incubated with $0 \%(\bullet), 1 \%(\mathbf{\Delta})$, and $2 \%(\square)$ corn oil (CO) at low pH (dashed line) and high $\mathrm{pH}$ (solid line) during $24 \mathrm{~h}$ of incubation (SEM $=0.01$; interaction between $\mathrm{pH}$ and time, $P<0.001$; interaction between $\mathrm{CO}$ and time, $P<0.001$ ).

g of FA, $P<0.001)$, trans-10, cis-12 18:2 (0.11 vs. 0.06 $\mathrm{g} / 100 \mathrm{~g}$ of $\mathrm{FA}, P<0.001$ ), and trans-10 18:1 (1.04 vs. $0.73 \mathrm{~g} / 100 \mathrm{~g}$ of FA, $P<0.001)$ and decreased concentrations of trans-11 18:1 (4.73 vs. $6.11 \mathrm{~g} / 100 \mathrm{~g}$ of FA, $P=0.001)$, cis-9,trans-11 $18: 2$ (0.23 vs. $0.26 \mathrm{~g} / 100$ $\mathrm{g}$ of FA, $P<0.001$ ), 18:0 (20.1 vs. $24.9 \mathrm{~g} / 100 \mathrm{~g}$ of

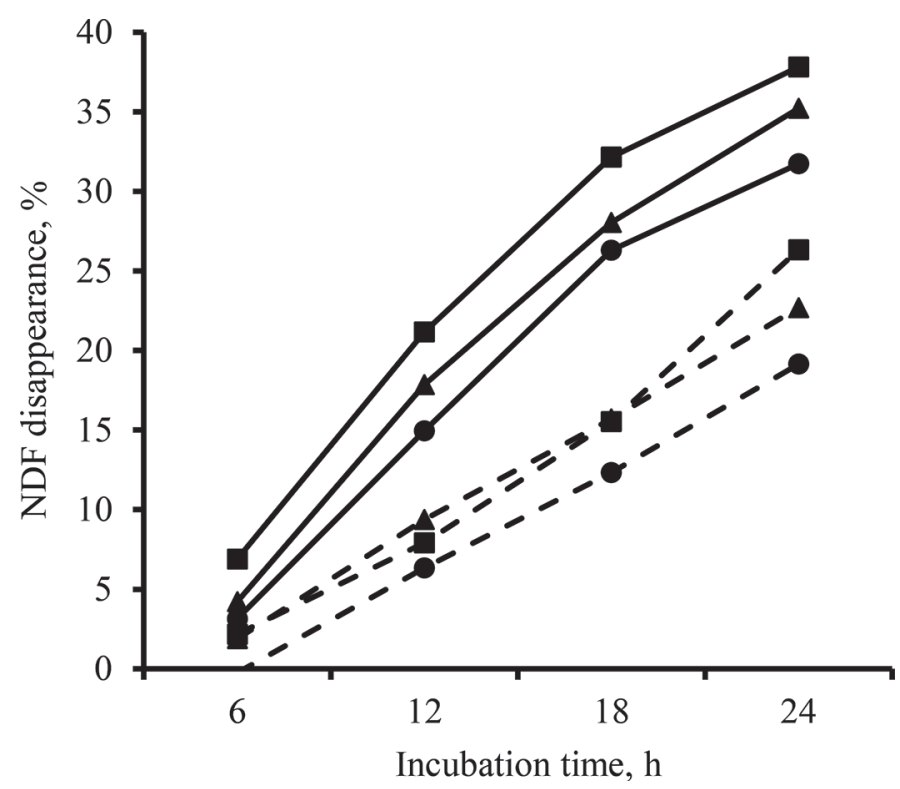

Figure 2. Disappearance of NDF in cultures incubated with $0 \%$ $(\bullet), 1 \%(\boldsymbol{\Delta})$, and $2 \%(\boldsymbol{\square})$ corn oil (CO) at low $\mathrm{pH}$ (dashed line) and high $\mathrm{pH}$ (solid line) during $24 \mathrm{~h}$ of incubation $(\mathrm{SEM}=0.69$; interaction among $\mathrm{pH}, \mathrm{CO}$, and time, $P=0.06$ ). The NDF disappearance was calculated by subtracting the weight of NDF residue in the cultures at $6,12,18$, and $24 \mathrm{~h}$ from the weight at $0 \mathrm{~h}$ and dividing by the weight at $0 \mathrm{~h}$.

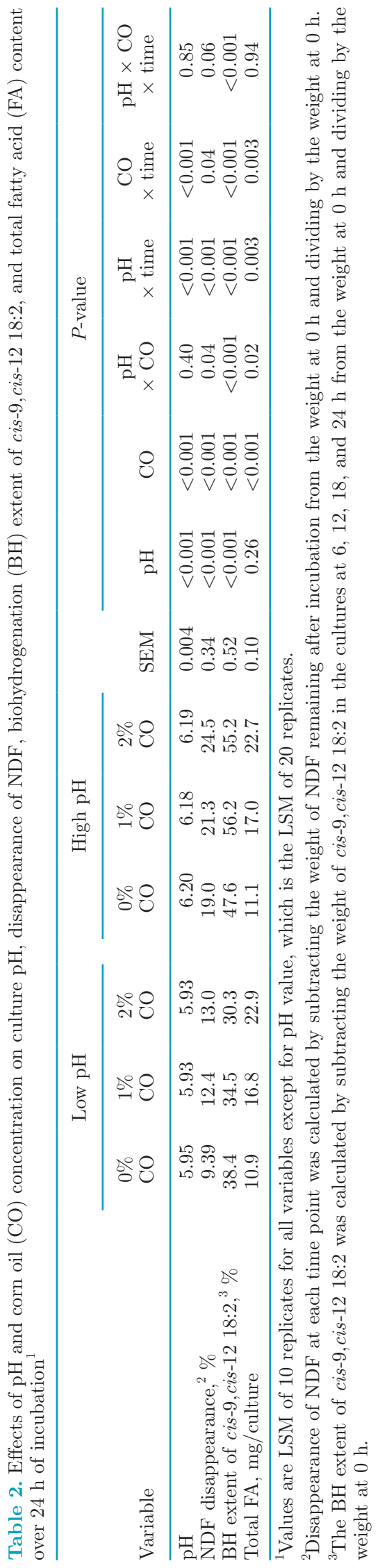




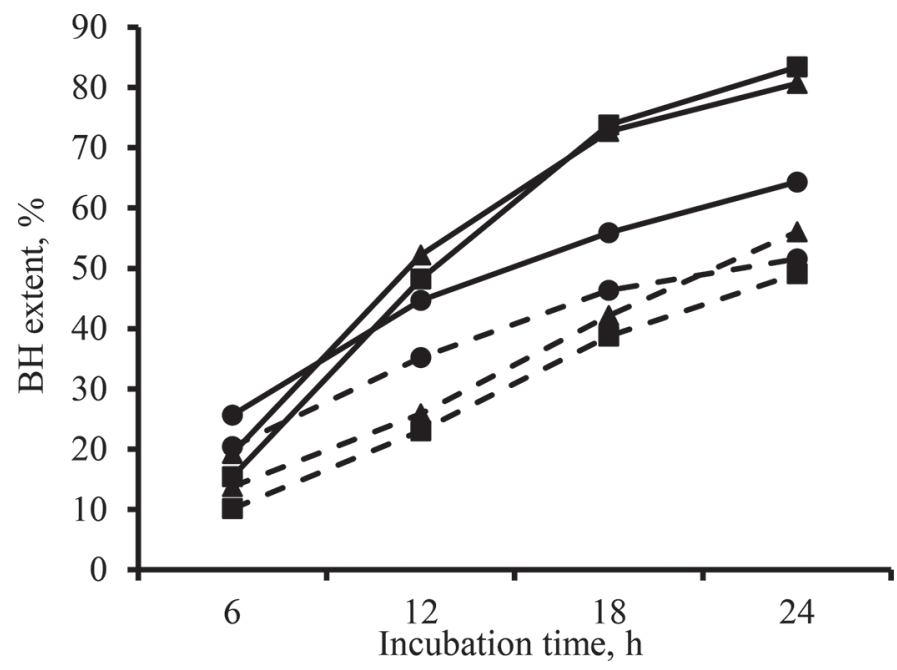

Figure 3. Biohydrogenation (BH) extent of cis-9,cis-12 18:2 in cultures incubated with $0 \%(\boldsymbol{\bullet}), 1 \%(\boldsymbol{\Delta})$, and $2 \%(\boldsymbol{\square})$ corn oil $(\mathrm{CO})$ at low $\mathrm{pH}$ (dashed line) and high $\mathrm{pH}$ (solid line) during $24 \mathrm{~h}$ of incubation ( $\mathrm{SEM}=1.03$; interaction among $\mathrm{pH}, \mathrm{CO}$, and time, $P<0.001$ ). The $\mathrm{BH}$ extent was calculated by subtracting the weight of cis-9, cis-12 $18: 2$ in the cultures at $6,12,18$, and $24 \mathrm{~h}$ from the weight at $0 \mathrm{~h}$ and dividing by the weight at $0 \mathrm{~h}$.

FA, $P<0.001)$, and total odd- and branched-chain FA (OBCFA; 3.78 vs. $4.43 \mathrm{~g} / 100 \mathrm{~g}$ of FA, $P<0.001$ ). Increasing $\mathrm{CO}$ increased concentrations of cis-9,cis-12 18:2 (7.88, 17.4, and $23.0 \mathrm{~g} / 100 \mathrm{~g}$ of FA, $P<0.001)$, cis-9,trans-11 18:2 (0.13, 0.27, and $0.33 \mathrm{~g} / 100 \mathrm{~g}$ of FA, $P<0.001)$, trans-10,cis-12 18:2 (0.04, 0.09, and 0.13 $\mathrm{g} / 100 \mathrm{~g}$ of FA, $P<0.001)$, trans-11 18:1 (3.46, 5.85, and $6.95 \mathrm{~g} / 100 \mathrm{~g}$ of FA, $P<0.001)$, trans-10 18:1 (0.72, 0.92 , and $1.03 \mathrm{~g} / 100 \mathrm{~g}$ of FA, $P<0.001)$, and OBCFA $(5.80,3.76$, and $2.75 \mathrm{~g} / 100 \mathrm{~g}$ of FA, $P<0.001)$ and decreased 18:0 (28.7, 21.7, and $17.1 \mathrm{~g} / 100 \mathrm{~g}$ of FA, $P<$ 0.001 ) for 0,1 , and $2 \% \mathrm{CO}$, respectively.

\section{Changes in FA Associated with BH of cis-9,cis-12 18:2 in Cultures During 24 h of Incubation}

The effects of culture $\mathrm{pH}$ and $\mathrm{CO}$ interacted with time to affect $\mathrm{FA}$ associated with $\mathrm{BH}$ of cis-9, cis-12 18:2 $(P<0.001)$, and their changes over time are shown in Figures 4, 5, and 6. Cis-9,cis-12 18:2 decreased during incubation in both low- and high-pH cultures but decreased faster at high $\mathrm{pH}$ than at low $\mathrm{pH}$, which resulted in 58\% lower concentration than low $\mathrm{pH}$ after $24 \mathrm{~h}$ of incubation. Furthermore, 18:0 increased during incubation in high-pH cultures $(P<0.001)$, and it had minor changes in low-pH cultures only after 18 and $24 \mathrm{~h}$ of incubation $(P=0.003)$. Cis-9,trans-11 18:2 increased during the first $12 \mathrm{~h}$ of incubation and decreased during the second $12 \mathrm{~h}$ of incubation in cultures with $\mathrm{CO}$ at high $\mathrm{pH}$ (Figure 5A, $P<0.05)$. Cis-9,trans-11 18:2 in- creased throughout $24 \mathrm{~h}$ of incubation in cultures with $\mathrm{CO}$ at low $\mathrm{pH}(P<0.01)$ except 18 to $24 \mathrm{~h}$. Compared with $0 \%$ CO, addition of CO increased cis-9,trans-11 18:2 during incubation at both low and high $\mathrm{pH}$ after 6 $\mathrm{h}$ of incubation. Generally, trans-11 18:1 increased in all cultures but increased at a higher rate in cultures containing $\mathrm{CO}$ than in those containing $0 \% \mathrm{CO}$ from 0 to $24 \mathrm{~h}$ of incubation (Figure 5B). Furthermore, trans-11 18:1 increased at a higher rate in cultures at high $\mathrm{pH}$ than those at low $\mathrm{pH}$ from 0 to $24 \mathrm{~h}$ of incubation.

Trans-10,cis-12 18:2 increased in cultures with 1 or $2 \% \mathrm{CO}$ at low $\mathrm{pH}$ during $24 \mathrm{~h}$ of incubation (Figure 6A). Furthermore, trans-10,cis-12 18:2 increased during the first $18 \mathrm{~h}$ of incubation and decreased during the last $6 \mathrm{~h}$ of incubation in cultures with 1 or $2 \%$ $\mathrm{CO}$ at high $\mathrm{pH}$. Compared with $0 \% \mathrm{CO}$, cultures with CO increased trans-10,cis-12 18:2 during incubation. Generally, trans-10 18:1 increased in all cultures during incubation, except those containing no $\mathrm{CO}$ at high $\mathrm{pH}$, which decreased trans-10 18:1 concentration (Figure $6 \mathrm{~B})$. Cultures at low $\mathrm{pH}$, regardless of $\mathrm{CO}$ concentration, increased trans-10 18:1 content faster than cultures at high $\mathrm{pH}$. Cultures containing $2 \% \mathrm{CO}$ at high $\mathrm{pH}$ ended the incubation period with lower trans-10 18:1 concentration than cultures containing $1 \% \mathrm{CO}$ at low $\mathrm{pH}$.

Figure 7 shows the interaction between culture $\mathrm{pH}$ and CO on concentrations of trans-10,cis-12 18:2 and trans-10 $18: 1$ after $24 \mathrm{~h}$ of incubation. Cultures containing $2 \% \mathrm{CO}$ at high $\mathrm{pH}$ had similar trans-10, cis-12 18:2 compared with those containing $1 \% \mathrm{CO}$ at low $\mathrm{pH}$. Increasing $\mathrm{CO}$ linearly increased concentrations of trans-10,cis-12 18:2 and trans-10 18:1 at both low and high $\mathrm{pH}$. However, rate of change of trans-10, cis-12 18:2 and trans-10 18:1 was greater at low $\mathrm{pH}(0.10$ and 0.64 , respectively) than at high $\mathrm{pH}(0.04$ and 0.38 , respectively) with increasing $\mathrm{CO}$.

\section{DISCUSSION}

Dietary PUFA are toxic to rumen bacteria, possibly by influencing membrane integrity or inhibiting bacterial metabolism (Maia et al., 2007). Rumen bacteria biohydrogenate PUFA to SFA through several isomerization and hydrogenation steps, reducing the toxicity of UFA. Numerous FA intermediates are formed during these processes. Cis-9,cis-12 18:2 is the most abundant PUFA in most cow diets based on corn and soy. Among all intermediates, cis-9,trans-11 18:2 and trans-11 18:1 are the major intermediates produced during $\mathrm{BH}$ of cis-9,cis-12 18:2 (Bauman and Griinari, 2003). However, specific dietary and rumen environment changes may result in more cis-9,cis-12 18:2 being biohydrogenated through alternative pathways, producing trans- 


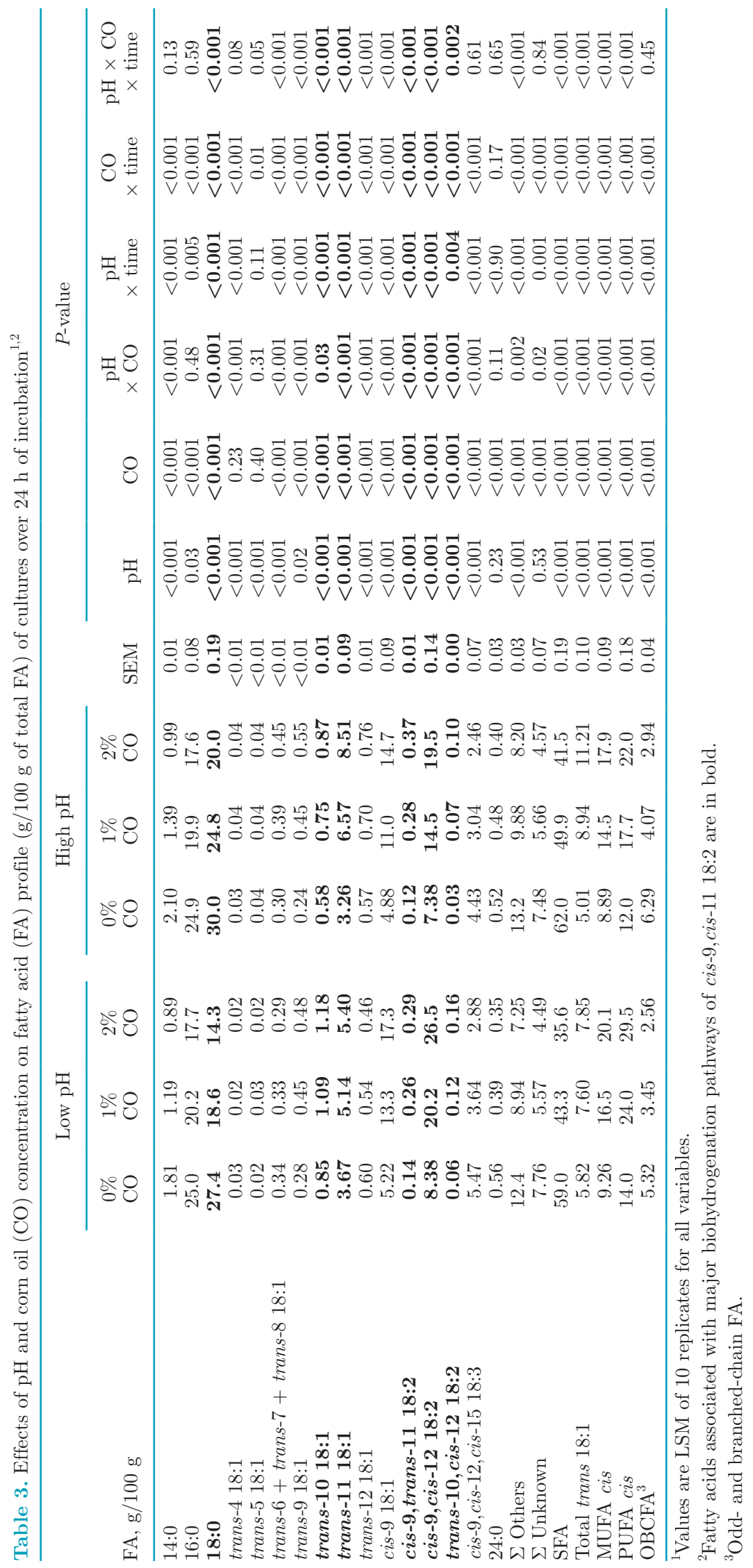


10,cis-12 18:2 and trans-10 18:1 as intermediates. It has been well documented that trans-10,cis-12 18:2 exhibits bioactive functions, including the inhibition of milk fat synthesis (Bauman et al., 2011). Similarly, trans-10 $18: 1$ is negatively correlated with milk fat content and is commonly used as a marker for MFD (Bauman et al., 2011). Diet-induced MFD is often caused by the inter-
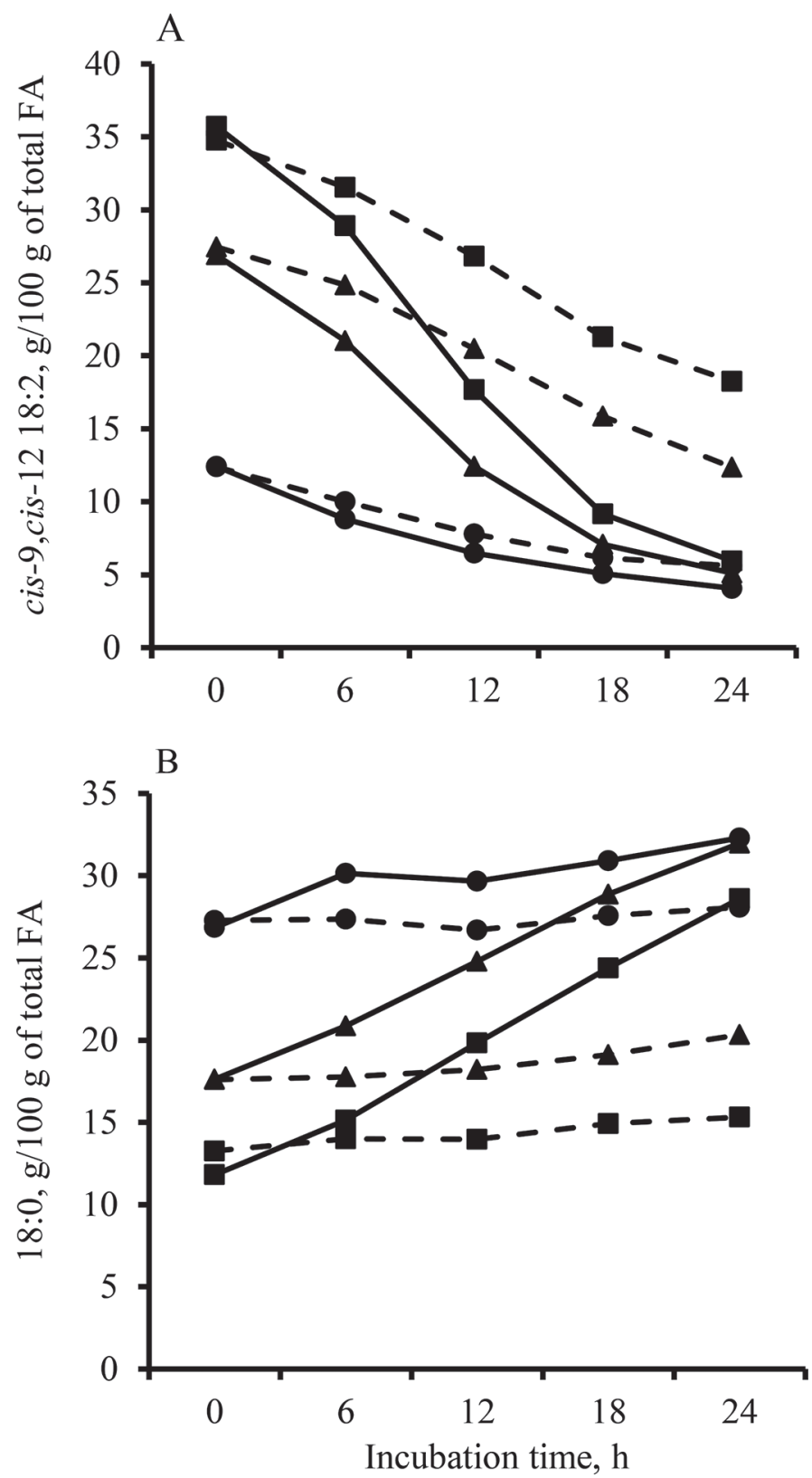

Figure 4. Concentrations of (A) cis-9, cis-12 18:2 and (B) 18:0 in cultures incubated with $0 \%(\bullet), 1 \%(\boldsymbol{\Delta})$, and $2 \%(\boldsymbol{\square})$ corn oil $(\mathrm{CO})$ at low $\mathrm{pH}$ (dashed line) and high $\mathrm{pH}$ (solid line) during $24 \mathrm{~h}$ of incubation $(\mathrm{SEM}=0.32$ and 0.43 , respectively; interaction among $\mathrm{pH}, \mathrm{CO}$, and time, both $P<0.001) . \mathrm{FA}=$ fatty acids
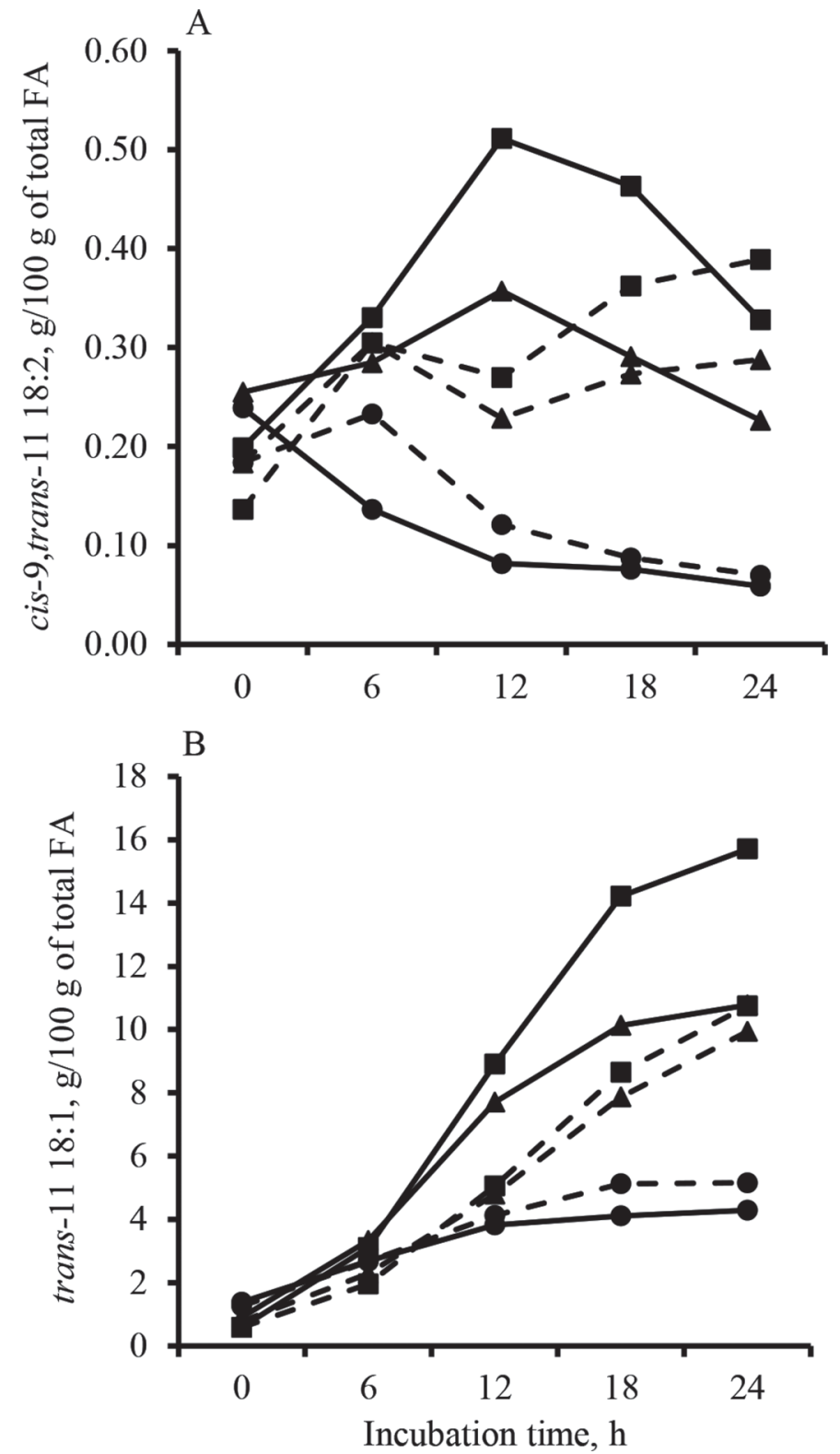

Figure 5. Concentrations of (A) cis-9,trans-11 18:2 and (B)

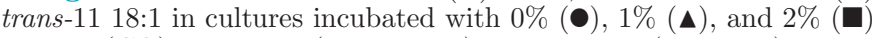
corn oil (CO) at low $\mathrm{pH}$ (dashed line) and high $\mathrm{pH}$ (solid line) during $24 \mathrm{~h}$ of incubation (SEM $=0.01$ and 0.20 , respectively; interaction among $\mathrm{pH}, \mathrm{CO}$, and time, both $P<0.001)$. FA = fatty acids.

action of several risk factors rather than a single diet characteristic. Diet-induced MFD requires the presence of both dietary PUFA and changes in rumen microbial populations or rumen environment, including alteration of $\mathrm{pH}$ (Bauman and Griinari, 2003). Although lower rumen $\mathrm{pH}$ is not a prerequisite for diet-induced MFD (Harvatine and Allen, 2006a,b), a decrease in rumen $\mathrm{pH}$ is often observed during diet changes, and rumen microbes have high-sensitivity $\mathrm{pH}$ changes (Russell and 

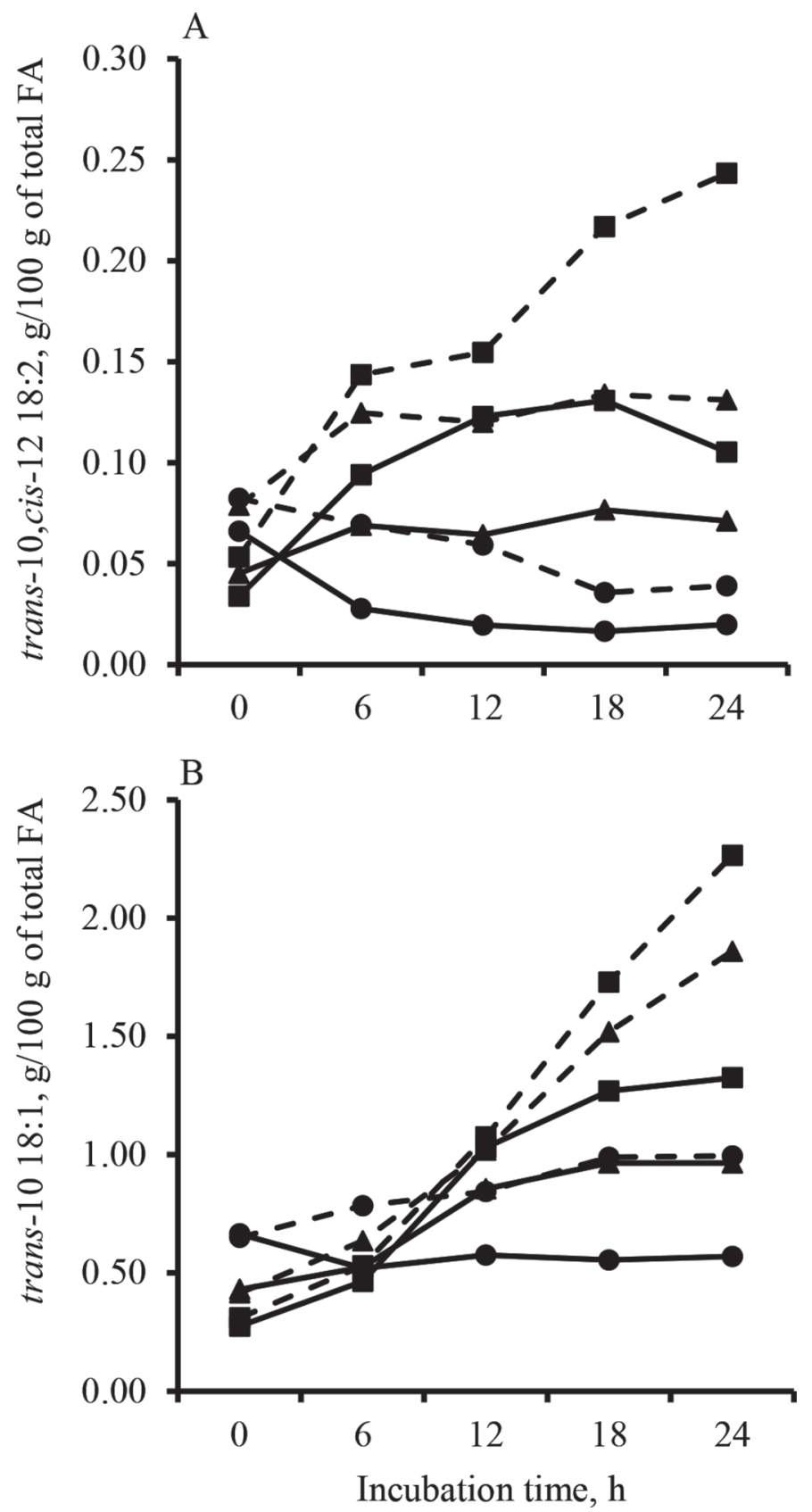

Figure 6. Concentrations of (A) trans-10,cis-12 18:2 and (B)

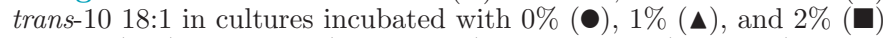
corn oil (CO) at low $\mathrm{pH}$ (dashed line) and high $\mathrm{pH}$ (solid line) during $24 \mathrm{~h}$ of incubation ( $\mathrm{SEM}=0.01$ and 0.03 , respectively; interaction among $\mathrm{pH}, \mathrm{CO}$, and time, both $P<0.01)$. $\mathrm{FA}=$ fatty acids.

Dombrowski, 1980). Therefore, our study used CO as a PUFA source and investigated the effect of the interaction between culture $\mathrm{pH}$ and $\mathrm{CO}$ concentration on disappearance of NDF and $\mathrm{BH}$ of cis-9,cis-12 18:2. By adding CO to alfalfa hay, we successfully increased concentrations of total FA and cis-9,cis-12 18:2. The FA profile of alfalfa hay in the current study is similar to
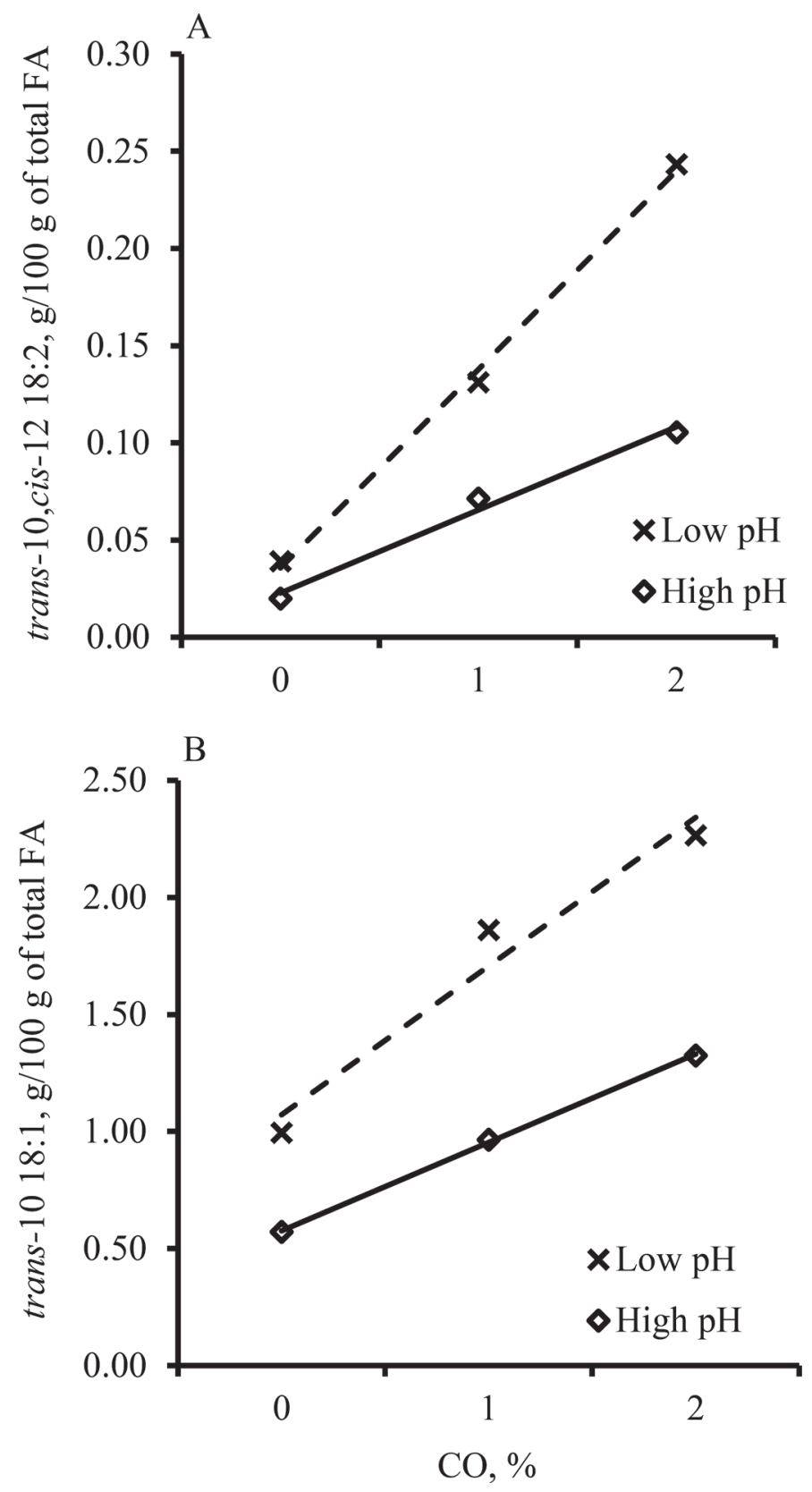

Figure 7. Interaction between $\mathrm{pH}$ and corn oil (CO) concentration and its effect on concentrations of (A) trans-10,cis-12 18:2 [low pH: trans-10, cis-12 18:2 (g/100 g of total FA $)=0.10 \times \mathrm{CO}(\%)-0.07, \mathrm{R}^{2}$ $=1.00$; high pH: trans -10, cis $-1218: 2(\mathrm{~g} / 100 \mathrm{~g}$ of total FA $)=0.04 \times$ $\mathrm{CO}(\%)-0.02, \mathrm{R}^{2}=0.99 ; P=0.04$ ] and $(\mathrm{B})$ trans-10 18:1 [low pH: trans-10 18:1 $(\mathrm{g} / 100 \mathrm{~g}$ of total FA $)=0.64 \times \mathrm{CO}(\%)+0.44, \mathrm{R}^{2}=$ 0.96; high pH: trans-10 18:1 (g/100 g of total FA $)=0.38 \times \mathrm{CO}(\%)$ $\left.+0.20, \mathrm{R}^{2}=1.00 ; P=0.003\right]$ in culture after $24 \mathrm{~h}$ of incubation. FA $=$ fatty acids.

that reported by Ribeiro et al. (2005). We also noticed a considerable amount of FA with carbon length more than $18(>\mathrm{C} 18)$ in alfalfa hay.

Several in vitro studies have tested the effects of $\mathrm{pH}$ on $\mathrm{BH}$ of PUFA across a wide range $(\mathrm{pH}=5.5-6.78$; 
AbuGhazaleh et al., 2005; Fuentes et al., 2011; Troegeler-Meynadier et al., 2014). However, the range of tested $\mathrm{pH}$ levels was very wide and less suitable for evaluating the sensitivity of $\mathrm{BH}$ to typical variations in rumen $\mathrm{pH}$. Low $\mathrm{pH}$ inhibits the growth of rumen bacteria and reduces rumen nutrient digestibility (Russell and Dombrowski, 1980; Russell and Wilson, 1996), and pH 5.8 is often chosen as a threshold for subacute acidosis (Beauchemin and Yang, 2005; Dohme et al., 2008; Mohammed et al., 2012). Therefore, we used a small $\mathrm{pH}$ range, 5.8 to 6.2 , in our study. Although buffer solutions were added to cultures to avoid the influence of accumulated acid on pH (Grant and Mertens, 1992a), we still observed some fluctuations in $\mathrm{pH}$ during culture incubation, which was also reported in previous in vitro studies (Troegeler-Meynadier et al., 2003, 2014). Following the incubation period, our low-pH cultures had a $\mathrm{pH}$ of $6.06 \pm 0.01$ and our high-pH cultures had a $\mathrm{pH}$ of $6.21 \pm 0.01$. Adding $\mathrm{CO}$ did not affect the $\mathrm{pH}$ of cultures in our study, and Honkanen et al. (2012) reported a similar result with no effect of cis-9,cis-12 18:2 on culture $\mathrm{pH}$.

Previous in vitro studies used hydrochloric acid and sodium hydroxide solution to adjust $\mathrm{pH}$ of buffer solutions (Troegeler-Meynadier et al., 2003; Zened et al., 2011; Lascano et al., 2016). However, this method might introduce excess salt into incubation cultures and influence the growth of bacteria. Citric acid can be metabolized by rumen bacteria (Van Soest, 1994) and was used in our study to minimize negative effects on fermentation. The effectiveness of using citric acid and phosphoric acid to adjust $\mathrm{pH}$ of phosphate-bicarbonate buffer has previously been evaluated (Grant and Mertens, 1992b); compared with phosphoric acid, citric acid was better able to maintain $\mathrm{pH}$ in rumen cultures during $72 \mathrm{~h}$ of fermentation. Compared with phosphoric acid, using citric acid to adjust buffer $\mathrm{pH}$ had no negative effect on NDF digestion, and low $\mathrm{pH}$ decreased NDF digestion compared with high pH (Grant and Mertens, 1992b). In our study, approximately 0.14 and $0.27 \mathrm{~g}$ of citric acid/culture was added to flasks to achieve high- and low-pH cultures, respectively. There are no studies, that we are aware of, that tested the effect of citric acid on BH. However, because rumen microbes are able to use citric acid as an energy source and produce acetic acid (Van Soest, 1994), we cannot rule out the effects of culture $\mathrm{pH}$ level on NDF digestion and $\mathrm{BH}$ being partially attributable to addition of citric acid.

Disappearance of NDF was determined to measure viability of cultures and effects of treatments. Cultures with $0 \%$ CO exhibited similar NDF disappearance as reported in continuous culture trials (Ribeiro et al., 2005). Both culture $\mathrm{pH}$ and $\mathrm{CO}$ affected NDF disap- pearance. In our study, compared with high $\mathrm{pH}$, low $\mathrm{pH}$ decreased NDF disappearance by $35 \%$. Low rumen $\mathrm{pH}$ is detrimental to cellulolytic bacteria (Russell and Wilson, 1996), and its relation to BH of UFA is discussed later. Grant and Mertens (1992b) reported that both rate and lag time of NDF digestion were affected negatively when $\mathrm{pH}$ dropped below 6.2. Although we did not measure the microbial biomass in the current study, OBCFA, a group of FA mainly synthesized by rumen microbes, have previously been used as a marker for estimation of rumen microbial mass (Vlaeminck et al., 2005). Low pH and the addition of CO decreased the concentration OBCFA, which suggests a reduction in microbial biomass. It is commonly recognized that UFA decreases NDF digestion. Hristov et al. (2005) found that $5 \%$ dietary linoleic acid-rich oil decreased total-tract NDF disappearance of beef cattle. A metaanalysis by Weld and Armentano (2017) showed that free oil supplementation decreased total-tract NDF digestibility but increased NDF digestibility in the rumen. Interestingly, we observed an increase in NDF disappearance with increasing $\mathrm{CO}$ concentration. This may be partially explained by the fact that fiber-rich alfalfa hay was the sole substrate in our in vitro culture. Bateman and Jenkins (1998) reported that up to $8 \%$ of soybean oil could be added to a high-fiber diet without depressing NDF disappearance. The maximum $\mathrm{CO}$ addition in our experiment was $2 \%$ of $\mathrm{DM}$, which is lower than in previous in vivo studies (Hristov et al., 2005; Weld and Armentano, 2017). Changes in rumen bacteria populations may be another reason for improved NDF disappearance in cultures with added CO. Although UFA are toxic to cellulolytic bacteria in pure culture (Maia et al., 2007), Hackmann and Firkins (2015) reported that Butyrivibrios might be able to synthesize long-chain FA de novo to compensate for the disruption of membrane integrity caused by the addition of cis-9,cis-12 18:2, which could also explain the interaction between culture $\mathrm{pH}, \mathrm{CO}$, and time on total FA content. Furthermore, Ivan et al. (2013) observed an increase in total cellulolytic bacteria in rumen fluid with $6 \%$ dietary linoleic acid-enriched oil, and Qiu et al. (2004) reported increases in cellulolytic bacteria when adding $1 \%$ linoleic acid in continuous culture. The effect of oil addition on rumen NDF digestion is debatable, and further research is needed to determine the effect of level of oil addition on NDF digestion and its interaction with diet.

We determined BH extent of cis-9,cis-12 18:2 via the disappearance of cis-9,cis-12 18:2 during the incubations. Several previous in vitro studies have reported higher BH extent of cis-9,cis-12 18:2 than our study during short-term incubation $(<8 \mathrm{~h}$; Troegeler-Meynadier et al., 2003, 2006; Zened et al., 2011; Honkanen et 
al., 2012). The difference may be due to several factors, including (1) higher culture $\mathrm{pH}$ (Troegeler-Meynadier et al., 2003, 2006; Honkanen et al., 2012), which increased BH of cis-9,cis-12 18:2 (Troegeler-Meynadier et al., 2006), and (2) addition of free cis-9,cis-12 18:2 instead of triglyceride (Zened et al., 2011; Honkanen et al., 2012), which avoided the inhibition of low culture $\mathrm{pH}$ on hydrolysis of triglyceride (Van Nevel and Demeyer, 1996). Even though we observed lower BH extents during the initial $12 \mathrm{~h}$ of incubation, $\mathrm{BH}$ extents after $24 \mathrm{~h}$ of incubation were comparable with previous batch culture studies (Troegeler-Meynadier et al., 2003, 2006; Zened et al., 2011). In a previous continuous culture trial with fluid and solid retention times of 10 and $18 \mathrm{~h}$, respectively, Ribeiro et al. (2005) reported $47 \%$ BH extent of cis-9,cis-12 18:2 in alfalfa hay, which was between 45 and $56 \%$ at 12 and $18 \mathrm{~h}$ of incubation in our study. An in vivo study reported over $80 \% \mathrm{BH}$ extent of cis-9,cis-12 18:2 with an approximately 40-h retention time in the rumen, which might have led to the higher $\mathrm{BH}$ extent compared with our study (Harvatine and Allen, 2006c).

Dietary PUFA and alteration of rumen $\mathrm{pH}$ are often requirements for diet-induced MFD (Bauman and Griinari, 2003; Bauman et al., 2011), and we observed interactions between these factors in our study. Increasing $\mathrm{CO}$ increased $\mathrm{BH}$ of cis-9,cis-12 18:2 in cultures with high $\mathrm{pH}$. This suggests that bacteria might be able to increase BH capacity to compensate for increasing PUFA, or a minor increase in dietary PUFA might stimulate or have no negative influence on bacterial growth. Ivan et al. (2013) reported that $6 \%$ dietary linoleic acid-enriched oil increased total cellulolytic bacteria in rumen fluid. Martin and Jenkins (2002) observed greater effects of culture $\mathrm{pH}$ on $\mathrm{BH}$ of UFA compared with other factors tested, including dilution rate and soluble carbohydrate concentration. Qiu et al. (2004) also reported that adding $1 \%$ of cis-9,cis-12 18:2 at culture $\mathrm{pH} 6.5$ increased BH of UFA by $33 \%$, whereas lower $\mathrm{pH}$ (5.8 vs. 6.5) decreased BH of UFA by $51 \%$. Previous studies have reported that low $\mathrm{pH}$ inhibits $\mathrm{BH}$ of cis-9,cis-12 18:2, decreases cis-9,trans-11 18:2, and increases formation of trans-10,cis-12 18:2 after no more than $8 \mathrm{~h}$ of incubation (Fuentes et al., 2011; TroegelerMeynadier et al., 2014). We also observed inhibition on $\mathrm{BH}$ of cis-9,cis-12 18:2 at low $\mathrm{pH}$ and accumulation of both trans-10,cis-12 18:2 and cis-9,trans-11 18:2 after $24 \mathrm{~h}$ of incubation. It is worth noting that the incubation times were only $6 \mathrm{~h}$ in previous studies (Van Nevel and Demeyer, 1996; Troegeler-Meynadier et al., 2014). In our 24-h incubation, cis-9,trans-11 18:2 increased during the first $12 \mathrm{~h}$ and decreased during the second 12 $\mathrm{h}$ in high-pH cultures containing $\mathrm{CO}$ but continued to increase in low-pH cultures containing $\mathrm{CO}$ across $24 \mathrm{~h}$.
Despite fluctuations, the proportion of trans-10,cis-12 18:2 to cis-9,trans-11 18:2 after $24 \mathrm{~h}$ of incubation was higher in low-pH cultures than in high-pH cultures (56 and 35\%, respectively). Troegeler-Meynadier et al. (2003) also observed that low $\mathrm{pH}$ increased the ratio of trans-10,cis-12 18:2 to cis-9,trans-11 18:2. Generally, cellulolytic bacteria are the major group of bacteria producing cis-9,trans-11 18:2 and trans-11 18:1 during BH of cis-9,cis-12 18:2 (Polan et al., 1964). Cellulolytic bacteria are sensitive to rumen $\mathrm{pH}$; when $\mathrm{pH}$ drops below 5.7, cell yields of Ruminococcus albus, Bacteroides succinogenes, Ruminococcus flavefaciens, and Butyrivibrio fibrisolvens decrease in pure cultures (Russell and Dombrowski, 1980). However, Megasphaera elsdenii, one of the reported producers of trans-10,cis-12 18:2 in vitro (Kim et al., 2002), is more tolerant to low $\mathrm{pH}$ and still grows in cultures until pH reaches 4.9 (Russell and Dombrowski, 1980). Therefore, it is more competitive than cellulolytic bacteria at low $\mathrm{pH}$. Overall, regardless of $\mathrm{CO}$ level, differences in culture $\mathrm{pH}$ appear to be the main driver of changes in $\mathrm{BH}$ extent.

Both in vitro and in vivo studies have shown that shift in trans-11 to trans-10 BH pathways or MFD can happen with increasing dietary UFA without changes in rumen $\mathrm{pH}$ (Harvatine and Allen, 2006a,b; Zened et al., 2013; Ventto et al., 2017). Results of our study are consistent with this observation because we observed that increasing $\mathrm{CO}$ resulted in the accumulation of trans-10,cis-12 18:2 and trans-10 18:1 in both high- and low-pH cultures. However, the accumulation of trans-10 FA intermediates was greater in cultures with low $\mathrm{pH}$ compared with high $\mathrm{pH}$. Previous studies found that M. elsdenii is low-pH tolerant and insensitive to PUFA (Russell and Dombrowski, 1980; Maia et al., 2007). This bacterium may be able to isomerize cis-9, cis- 12 18:2 to trans-10, cis-12 18:2 in culture, whereas growth and metabolism of other bacteria are inhibited by low $\mathrm{pH}$ and high PUFA. At high $\mathrm{pH}, \mathrm{CO}$ increased isomerization of cis-9, cis-12 18:2 but decreased hydrogenation of trans 18:1 to 18:0. This suggests that bacteria associated with the last step of $\mathrm{BH}$ might be more sensitive to PUFA than bacteria associated with other steps of BH. Clostridium proteoclasticum has a lower tolerance to cis-9,cis-12 18:2 than Butyrivibrio, which transfer cis-9,cis-12 18:2 to CLA isomers (Jenkins et al., 2008). Maia et al. (2007) observed similar results in a pure bacterial culture study, with butyrate-producing bacteria (e.g., Butyrivibrio proteoclasticus) being more sensitive to UFA than other bacteria. Additionally, compared with high $\mathrm{pH}$, increasing $\mathrm{CO}$ in cultures with low $\mathrm{pH}$ resulted in greater decreases in iso 16:0, an OBCFA derived from rumen microbes (Supplemental Table S2, https://doi.org/10.3168/jds.2019-16581). Colman et al. (2010) suggested that compared with milk 
fat content or trans-10 18:1, iso 16:0 content in milk is a better indicator of acidosis (Colman et al., 2010). Our study results suggest that dietary UFA level may also need to be considered if using milk iso 16:0 as an indicator of acidosis.

\section{CONCLUSIONS}

Low culture $\mathrm{pH}$ decreased both disappearance of $\mathrm{NDF}$ and the BH extent of cis-9,cis-12 18:2 and increased the accumulation of $\mathrm{BH}$ intermediates (trans 18:1 and CLA isomers). In particular, low $\mathrm{pH}$ resulted in a greater increase in both trans-10 18:1 and trans10,cis-12 18:2 compared with high $\mathrm{pH}$. Addition of CO increased disappearance of $\mathrm{NDF}$ and $\mathrm{BH}$ extent of cis9,cis-12 18:2. Accumulation of both trans-10 18:1 and trans-10,cis-12 was greater with increasing CO at low $\mathrm{pH}$ compared with high $\mathrm{pH}$. This implies a higher risk for MFD when diets contain high cis-9, cis-12 18:2 concentration, provided by vegetable oil, along with factors that may cause low rumen $\mathrm{pH}$, and it is more important to maintain adequate rumen $\mathrm{pH}$ to reduce risk for MFD. Culture $\mathrm{pH}$ interacted with $\mathrm{CO}$ concentration to affect $\mathrm{BH}$ of UFA and disappearance of NDF in batch culture, as the effects were greater at low culture $\mathrm{pH}$ than at high culture $\mathrm{pH}$.

\section{ACKNOWLEDGMENTS}

We acknowledge the Animal Agriculture Initiative at Michigan State University for financial support of this research. We also thank C. L. Preseault, D. Main, J. Boerman, J. Garver, L. Worden, T. Bryant (all in the Department of Animal Science, Michigan State University, East Lansing), the staff of the Michigan State University Dairy Cattle Field Laboratory for their assistance in this experiment, and S. E. Schmidt (Department of Animal Science, Michigan State University, East Lansing) for her assistance with editing the manuscript.

\section{REFERENCES}

AbuGhazaleh, A. A., M. B. Riley, E. E. Thies, and T. C. Jenkins. 2005. Dilution rate and $\mathrm{pH}$ effects on the conversion of oleic acid to trans C18:1 positional isomers in continuous cultures. J. Dairy Sci. 88:4334-4341.

Allen, M. S. 1997. Relationship between fermentation acid production in the rumen and the requirement for physically effective fiber. J. Dairy Sci. 80:1447-1462.

Bateman, H. G., and T. C. Jenkins. 1998. Influence of soybean oil in high fiber diets fed to nonlactation cows on ruminal unsaturated fatty acids and nutrient digestibility. J. Dairy Sci. 81:2451-2458.

Bauman, D. E., and J. M. Griinari. 2003. Nutritional regulation of milk fat synthesis. Annu. Rev. Nutr. 23:203-227.
Bauman, D. E., K. J. Harvatine, and A. L. Lock. 2011. Nutrigenomics, rumen-derived bioactive fatty acids, and the regulation of milk fat synthesis. Annu. Rev. Nutr. 31:299-319.

Beauchemin, K. A., and W. Z. Yang. 2005. Effects of physically effective fiber on intake, chewing activity, and ruminal acidosis for dairy cows fed diets based on corn silage. J. Dairy Sci. 88:2117-2129.

Colman, E., W. B. Fokkink, M. Craninx, J. R. Newbold, B. De Baets, and V. Fievez. 2010. Effect of induction of subacute ruminal acidosis on milk fat profile and rumen parameters. J. Dairy Sci. 93:4759-4773.

Dohme, F., T. J. DeVries, and K. A. Beauchemin. 2008. Repeated ruminal acidosis challenges in lactating dairy cows at high and low risk for developing acidosis: Ruminal pH. J. Dairy Sci. 91:35543567.

Fuentes, M. C., S. Calsamiglia, V. Fievez, M. Blanch, and D. Mercadal. 2011. Effect of $\mathrm{pH}$ on ruminal fermentation and biohydrogenation of diets rich in omega- 3 or omega- 6 fatty acids in continuous culture of ruminal fluid. Anim. Feed Sci. Technol. 169:35-45.

Goering, H. K., and P. J. Van Soest. 1970. Forage Fiber Analysis (Apparatus, Reagents, Procedures, and Some Applications). Agricultural Handbook 379. ARS-USDA, Washington, DC.

Grant, R. J., and D. R. Mertens. 1992a. Influence of buffer pH and raw corn starch addition on in vitro fiber digestion kinetics. J. Dairy Sci. $75: 2762-2768$.

Grant, R. J., and D. R. Mertens. 1992b. Development of buffer systems for $\mathrm{pH}$ control and evaluation of $\mathrm{pH}$ effects on fiber digestion in vitro. J. Dairy Sci. 75:1581-1587.

Hackmann, T. J., and J. L. Firkins. 2015. Electron transport phosphorylation in rumen butyrivibrios: Unprecedented ATP yield for glucose fermentation to butyrate. Front. Microbiol. 6:622.

Harvatine, K. J., and M. S. Allen. 2006a. Effects of fatty acid supplements on milk yield and energy balance of lactating dairy cows. J. Dairy Sci. 89:1081-1091.

Harvatine, K. J., and M. S. Allen. 2006b. Effects of fatty acid supplements on feed intake, and feeding and chewing behavior of lactating dairy cows. J. Dairy Sci. 89:1104-1112.

Harvatine, K. J., and M. S. Allen. 2006c. Fat supplements affect fractional rates of ruminal fatty acid biohydrogenation and passage in dairy cows. J. Nutr. 136:677-685.

Honkanen, A. M., J. M. Griinari, A. Vanhatalo, S. Ahvenjärvi, V. Toivonen, and K. J. Shingfield. 2012. Characterization of the disappearance and formation of biohydrogenation intermediates during incubations of linoleic acid with rumen fluid in vitro. J. Dairy Sci. 95:1376-1394.

Hristov, A. N., L. R. Kennington, M. A. McGuire, and C. W. Hunt 2005. Effect of diets containing linoleic acid or oleic acid rich oils on ruminal fermentation and nutrient digestibility, and performance and fatty acid composition of adipose and muscle tissues of finishing cattle. J. Anim. Sci. 83:1312-1321.

Ivan, M., H. V. Petit, J. Chiquette, and A. D. G. Wright. 2013. Rumen fermentation and microbial population in lactating dairy cows receiving diets containing oilseeds rich in $\mathrm{C}-18$ fatty acids. Br. J. Nutr. 109:1211-1218.

Jenkins, T. C. 2010. Technical note: Common analytical errors yielding inaccurate results during analysis of fatty acids in feed and digesta samples. J. Dairy Sci. 93:1170-1174.

Jenkins, T. C., R. J. Wallace, P. J. Moate, and E. E. Mosley. 2008. Board-invited review: Recent advances in biohydrogenation of unsaturated fatty acids within the rumen microbial ecosystem. J. Anim. Sci. 86:397-412.

Kim, Y. J., R. H. Liu, D. R. Bond, and J. B. Russell. 2000. Effect of linoleic acid concentration on conjugated linoleic acid production by Butyrivibrio fibrisolvens A38. Appl. Environ. Microbiol. 66:5226-5230

Kim, Y. J., R. H. Liu, J. L. Rychlik, and J. B. Russell. 2002. The enrichment of a ruminal bacterium (Megasphaera elsdenii YJ-4) that produces the trans-10, cis-12 18:2 isomer of conjugated linoleic acid. J. Appl. Microbiol. 92:976-982.

Lascano, G. J., M. Alende, L. E. Koch, and T. C. Jenkins. 2016. Changes in fermentation and biohydrogenation intermediates in 
continuous cultures fed low and high level of fat with increasing rates of starch degradability. J. Dairy Sci. 99:6334-6341.

Maia, M. R. G., L. C. Chaudhary, L. Figueres, and R. J. Wallace. 2007. Metabolism of polyunsaturated fatty acids and their toxicity to the microflora of the rumen. Antonie Van Leeuwenhoek 91:303-314.

Martin, S. A., and T. C. Jenkins. 2002. Factors affecting conjugated linoleic acid and trans-C18:1 fatty acid production by mixed ruminal bacteria. J. Anim. Sci. 80:3347-3352.

Mertens, D. R. 2002. Gravimetric determination of amylase-treated neutral detergent fiber in feeds using refluxing in beakers or crucibles: Collaborative study. J. AOAC Int. 85:1217-1240.

Mohammed, R., D. M. Stevenson, P. J. Weimer, G. B. Penner, and K. A. Beauchemin. 2012. Individual animal variability in ruminal bacterial communities and ruminal acidosis in primiparous Holstein cows during the periparturient period. J. Dairy Sci. 95:6716-6730.

Polan, C. E., J. J. McNeill, and S. B. Tove. 1964. Biohydrogenation of unsaturated fatty acids by rumen bacteria. J. Bacteriol. 88:10561064.

Qiu, X., M. L. Eastridge, K. E. Griswold, and J. L. Firkins. 2004 Effects of substrate, passage rate, and $\mathrm{pH}$ in continuous culture on flows of conjugated linoleic acid and trans C18:1. J. Dairy Sci. 87:3473-3479

Ribeiro, C. V. D. M., S. K. R. Karnati, and M. L. Eastridge. 2005 Biohydrogenation of fatty acids and digestibility of fresh alfalfa or alfalfa hay plus sucrose in continuous culture. J. Dairy Sci. 88:4007-4017.

Russell, J. B., and D. B. Dombrowski. 1980. Effect of pH on the efficiency of growth by pure cultures of rumen bacteria in continuous culture. Appl. Environ. Microbiol. 39:604-610.

Russell, J. B., and D. B. Wilson. 1996. Why are ruminal cellulolytic bacteria unable to digest cellulose at low pH? J. Dairy Sci. 79:1503-1509.

Sayre, K. D., and P. J. Van Soest. 1972. Comparison of types of fermentation vessels for an in vitro artificial rumen procedure. J. Dairy Sci. 55:1496-1498.

Shingfield, K. J., and R. J. Wallace. 2014. Synthesis of conjugated linoleic acid in ruminants and humans. Pages 1-65 in Conjugated Linoleic Acids and Conjugated Vegetable Oils. B. Sels and A. Philippaerts, ed. The Royal Society of Chemistry, London, UK.
Troegeler-Meynadier, A., L. Bret-Bennis, and F. Enjalbert. 2003. Effects of $\mathrm{pH}$ and concentrations of linoleic and linolenic acids on extent and intermediates of ruminal biohydrogenation in vitro. J. Dairy Sci. 86:4054-4063.

Troegeler-Meynadier, A., L. Bret-Bennis, and F. Enjalbert. 2006. Rates and efficiencies of reactions of ruminal biohydrogenation of linoleic acid according to $\mathrm{pH}$ and polyunsaturated fatty acids concentration. Reprod. Nutr. Dev. 46:713-724.

Troegeler-Meynadier, A., C. Palagiano, and F. Enjalbert. 2014. Effects of $\mathrm{pH}$ and fermentative substrate on ruminal metabolism of fatty acids during short-term in vitro incubation. J. Anim. Physiol. Anim. Nutr. (Berl.) 98:704-713.

Van Nevel, C. J., and D. I. Demeyer. 1996. Influence of pH on lipolysis and biohydrogenation of soybean oil by rumen contents in vitro. Reprod. Nutr. Dev. 36:53-63.

Van Soest, P. J. 1994. Nutritional Ecology of the Ruminant. 2nd ed. Cornell University Press, Ithaca, NY.

Ventto, L., H. Leskinen, P. Kairenius, T. Stefanski, A. R. Bayat, J. Vikki, and K. J. Shingfield. 2017. Diet-induced milk fat depression is associated with alterations in ruminal biohydrogenation pathways and formation of novel fatty acid intermediates in lactating cows. Br. J. Nutr. 117:364-376.

Vlaeminck, B., C. Dufour, A. M. van Vuuren, A. R. J. Cabrita, R J. Dewhurst, D. Demeyer, and V. Fievez. 2005. Use of odd and branched-chain fatty acids in rumen contents and milk as a potential microbial marker. J. Dairy Sci. 88:1031-1042.

Weld, K. A., and L. E. Armentano. 2017. The effects of adding fat to diets of lactating dairy cows on total-tract neutral detergent fiber digestibility: A meta-analysis. J. Dairy Sci. 100:1766-1779.

Zened, A., F. Enjalbert, M. C. Nicot, and A. Troegeler-Meynadier. 2013. Starch plus sunflower oil addition to the diet of dry dairy cows results in a trans-11 to trans-10 shift of biohydrogenation. J. Dairy Sci. 96:451-459.

Zened, A., A. Troegeler-Meynadier, M. C. Nicot, S. Combes, L. Cauquil, Y. Farizon, and F. Enjalbert. 2011. Starch and oil in the donor cow diet and starch in substrate differently affect the in vitro ruminal biohydrogenation of linoleic and linolenic acids. J. Dairy Sci. 94:5634-5645. 